\title{
Synthesis and characterization of triphenylamine and Bbis(indolyl)methane center-functionalized polymer via reversible addition-fragmentation chain transfer polymerization
}

\author{
Jie Xu, Wei Zhang, Nianchen Zhou, Jian Zhu, Zhenping Cheng and Xiulin Zhu*
}

*Key Lab. of Organic Synthesis of Jiangsu Province, School of Chemistry and Chemical Engineering of Soochow (Suzhou) University, Suzhou 215006, China; fax: (+86) 512 6511 2796; e-mail: xlzhu@suda.edu.cn

(Received: 28 November, 2007; published: 12 February, 2008)

\begin{abstract}
A novel bis-functional reversible addition-fragmentation chain transfer (RAFT) agent bearing triphenylamine (TPA) and bis(indolyl)methane (BIM) groups, \{4-[bis(1-carbodithioic acid benzyl ester-indol-3-yl)methyl]phenyl\}diphenylamine (BCIMPDPA), was synthesized and successfully used as the RAFT agent to mediate the polymerization of styrene (St). The polymerization results showed that reversible addition-fragmentation chain transfer (RAFT) polymerization of St could be well controlled. The kinetic plot showed it was of first order and the numberaverage molecular weight $\left(M_{\mathrm{n}(\mathrm{GPC})}\right)$ of the polymer measured by GPC increased linearly with monomer conversion, simultaneously, the molecular weight distribution of the polymer was also relatively narrow. In addition, the existence of the TPA and BIM groups in the middle of polymer chain was confirmed by chain extension reaction and ${ }^{1} \mathrm{H}$ NMR spectrum. The optical properties of the functionalized polystyrene (PS) in chloroform solution were also investigated. Furthermore, the redox process of the RAFT agent and the functionalized PS were studied by cyclic voltammetry method.
\end{abstract}

\section{Introduction}

Preparation of well-defined polymers containing functional groups with potential activity plays an increasingly important role in many application fields [1-4]. The emergence of living free radical polymerization (LFRP) methods affords effective tools to achieve such ideal materials [5-7]. Among those reported LFRP methods, nitroxide-mediated polymerization (NMP) [8], atom transfer radical polymerization (ATRP) [9, 10], and reversible addition-fragmentation chain transfer (RAFT) polymerization $[11,12]$ have been extensively reported. As one powerful LFRP method, the RAFT technique has been widely used to synthesize functional monomers because of its high degree of compatibility with a wide range of functional monomers and good tolerance of water and oxygen in the systems [13]. In principle, all common radical polymerizations can be actualized with the RAFT process in the presence of efficient RAFT agents. According to the mechanism of RAFT polymerization proposed by Rizzardo et al. [11], the polymer obtained by RAFT process contains the moieties of RAFT agent in the polymer chain. As a result, the various functional groups can be easily introduced into the polymer chains via RAFT polymerization by designing the structures of the RAFT agents (i.e., by selecting specific structures for activating and leaving groups of the dithioester). A number of well-defined polymers have been synthesized through RAFT polymerization [14-20]. 
The telechelic poly( $n$-butyl acrylate)s with dicarboxylic acid functional groups was synthesized via RAFT polymerization [21]. It was also reported that the biotinylated stimuli-responsive polymer and diblock copolymer were synthesized by RAFT polymerization using biotinylated trithiocarbonate as RAFT agent [22].

Triarylamines are unique molecules possessing multiple functions, such as redox, fluorescence and ferromagnetism [23]. Particularly, triarylamine derivatives can exhibit good electron-donating property, low ionization potential, suitable hole mobility (generally at $10^{-3} \sim 10^{-4} \mathrm{~cm}^{2} \mathrm{~V}^{-1} \mathrm{~s}^{-1}$ ), good amorphous film formation property and high thermal stability, which facilitates their use as hole-transport material and play an important role in electronic devices, such as organic light-emitting diodes (OLEDs), organic photoreceptor devices and photo cells [23, 24-26]. Various polymers with triarylamine side groups were synthesized by free radical polymerization utilizing the gel effect and also prepared by living radical polymerization such as nitroxide-mediated polymerization (NMP) in order to obtain the polymer with the narrow molecular weight distributions $\left(M_{\mathrm{w}} / M_{\mathrm{n}}\right)$ and predetermined molecular weight [27]. On the other hand, indole and its derivatives are also important intermediates in organic synthesis and exhibit various physiological properties and pharmacological activities [28]. Bis(indolyl)methanes are found in cruciferous plants which are well known to promote beneficial estrogen metabolism [29] and introduces apoptosis in human cancer cell. Therefore it is highly desirable to introduce the triphenylamine (TPA) and bis(indolyl)methane (BIM) groups into the polymer chain.

In this work, the well-defined polystyrene (PS) functionalized with TPA and BIM moieties was prepared via RAFT polymerization of styrene (St) mediated by 44[bis(1-carbodithioic acid benzyl ester-indol-3-yl)methyl]phenyl\}diphenylamine (BCIMPDPA). The optical properties and the redox process of the RAFT agent and the center-functionalized PS were further investigated.

\section{Results and discussion}

\section{RAFT polymerizations of St mediated by BCIMPDPA}

RAFT thermal-initiated polymerization of St at $115^{\circ} \mathrm{C}$ was carried out in the presence of BCIMPDPA and the results are shown in Figures 1 and 2 , respectively. As presented in Figure 1, the linear relationship between $\ln \left([\mathrm{M}]_{0} /[\mathrm{M}]\right)$ and the polymerization time, where $[\mathrm{M}]_{0}$ and $[\mathrm{M}]$ were the concentrations of St at time zero and $t$, respectively, indicated that the radical concentration remained constant during the polymerization processes. Furthermore, as shown in Figure 2, the numberaverage molecular weight $\left(M_{n(G P C)}\right)$ increased almost linearly with monomer conversion, which was consistent with the polymerization proceeding in a controlled fashion. However, the $M_{\mathrm{n}(\mathrm{GPC})}$ was slightly higher than the theoretical value $\left(M_{\mathrm{n} \text { (th) }}\right.$, calculated via equation 1) in the early stage of the polymerization, and lower than the $M_{\mathrm{n}(\mathrm{th})}$ at relatively high monomer conversion. At the beginning of the polymerization, some positive deviation of $M_{\mathrm{n}(\mathrm{GPC})}$ from the theoretical value $\left(M_{\mathrm{n}(\mathrm{th})}\right)$ may be due to the incomplete usage of RAFT agent. And at relatively high monomer conversion, some negative deviation may be due to some side reactions of the initiator or initiator-derived radicals with the RAFT agent [30-31]. The molecular weight distribution of polymer obtained was relatively narrow. These results showed that BCIMPDPA was an effective RAFT agent for the RAFT polymerization of St. 
$M_{n, t h}=\frac{\text { monomer weight }}{\text { mole of Rafting agent }} \times$ conversion $+M_{R A F T}$

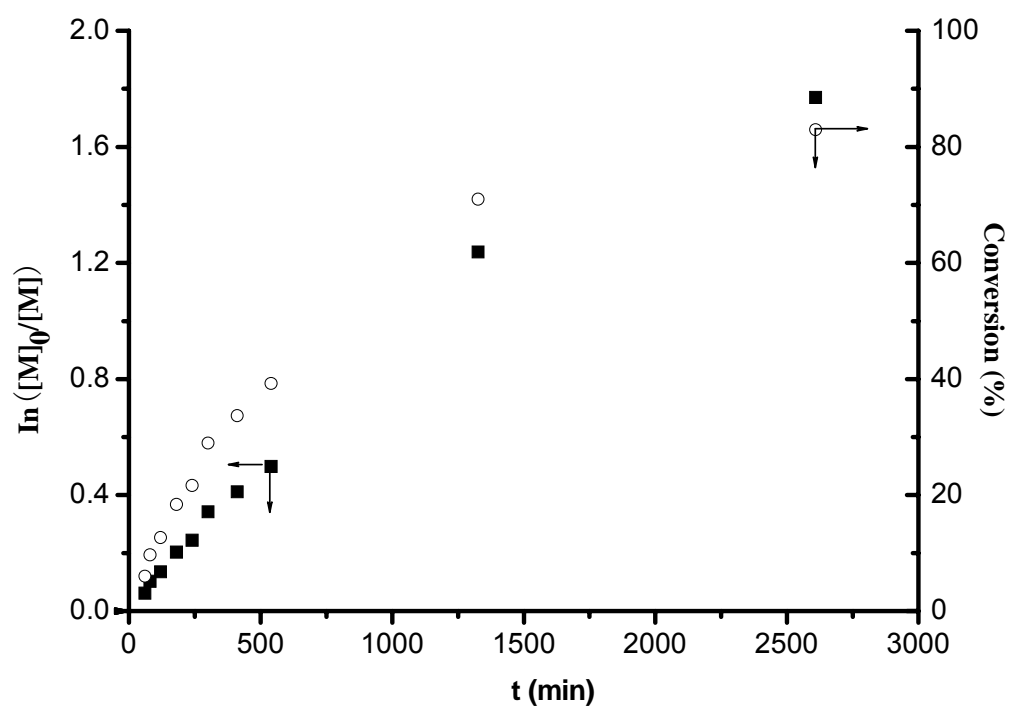

Fig. 1. Relationship between $\ln \left([\mathrm{M}]_{0} /[\mathrm{M}]\right)$ and the polymerization time for the RAFT polymerizations of St at $115^{\circ} \mathrm{C}$ in bulk ([St $\left.]_{0}:[\mathrm{BCIMPDPA}]_{0}=800: 1\right)$.

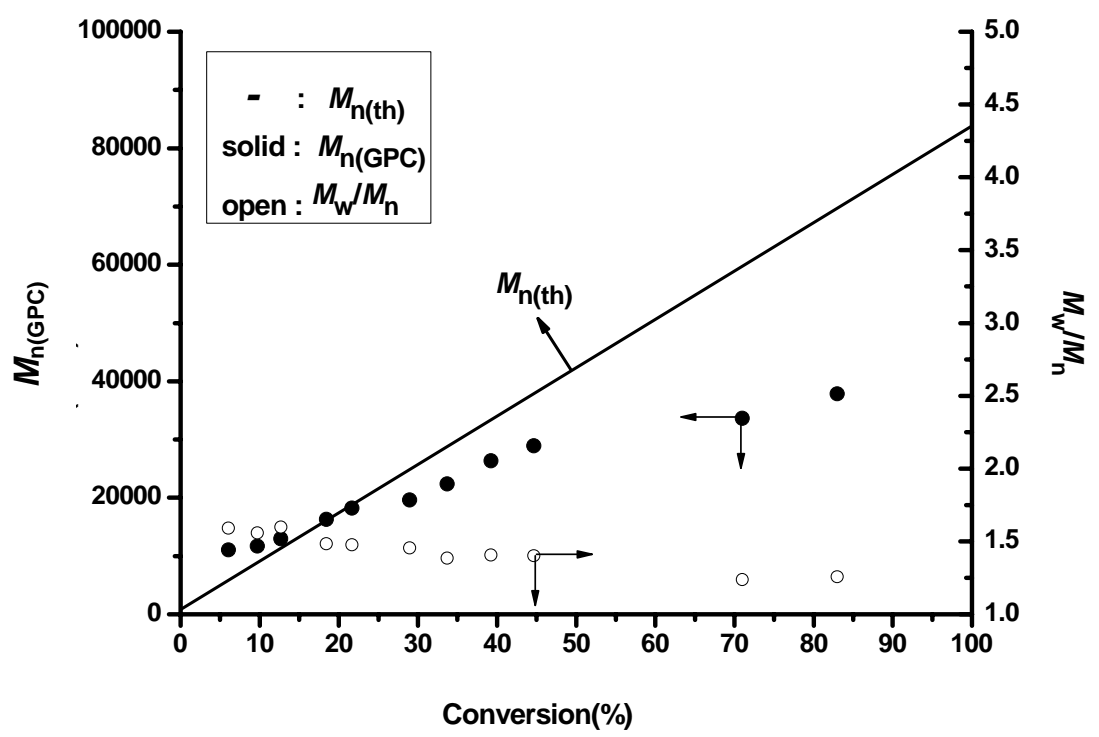

Fig. 2. Dependence of the molecular weight and molecular weight distribution on the monomer conversion for the RAFT polymerization of St at $115{ }^{\circ} \mathrm{C}$. Polymerization conditions are same as in Figure 1.

End group analysis and the chain extension experiment

In order to prove the existence of RAFT moieties in the PS chain, the PS was characterized by ${ }^{1} \mathrm{H}$ NMR spectrum. Figure 3 showed the ${ }^{1} \mathrm{H}$ NMR spectrum of the 
TPA and BIM groups center-functionalized PS obtained via RAFT polymerization using BCIMPDPA as RAFT agent. The peaks at $5.53 \mathrm{ppm}(\mathrm{a}), 8.92 \mathrm{ppm}$ (b) and the peaks at 4.47-5.10 (ppm) (c) were corresponding to the methenyl proton of bis(indolyl)methyne group, the phenyl proton in indole and the methenyl proton in benzyl group, respectively. These results indicated that triphenylamine (TPA) and bis(indolyl)methane (BIM) moieties of the RAFT agent were attached to the center of the polymer chain. Furthermore, the molecular weight of PS can be calculated from Figure $3\left(M_{\mathrm{n}(\mathrm{NMR})}=6300\right.$, by Equation 2$)$, which was close to the value measured by GPC $\left(M_{n(G P C)}=6200 \mathrm{~g} / \mathrm{mol}\right)$, which indicated that BCIMPDPA was an effective RAFT agent for the polymerization of St.

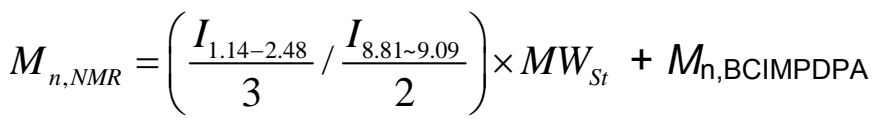

Where $I_{1.14-2.48}$ : the integral of the signals at $1.14-2.48 \mathrm{ppm}, I_{8.81-9.09}$ : the integral of the signals at 8.81-9.09 ppm, $\mathrm{MW}_{\mathrm{St}}$ : molecular weight of St.

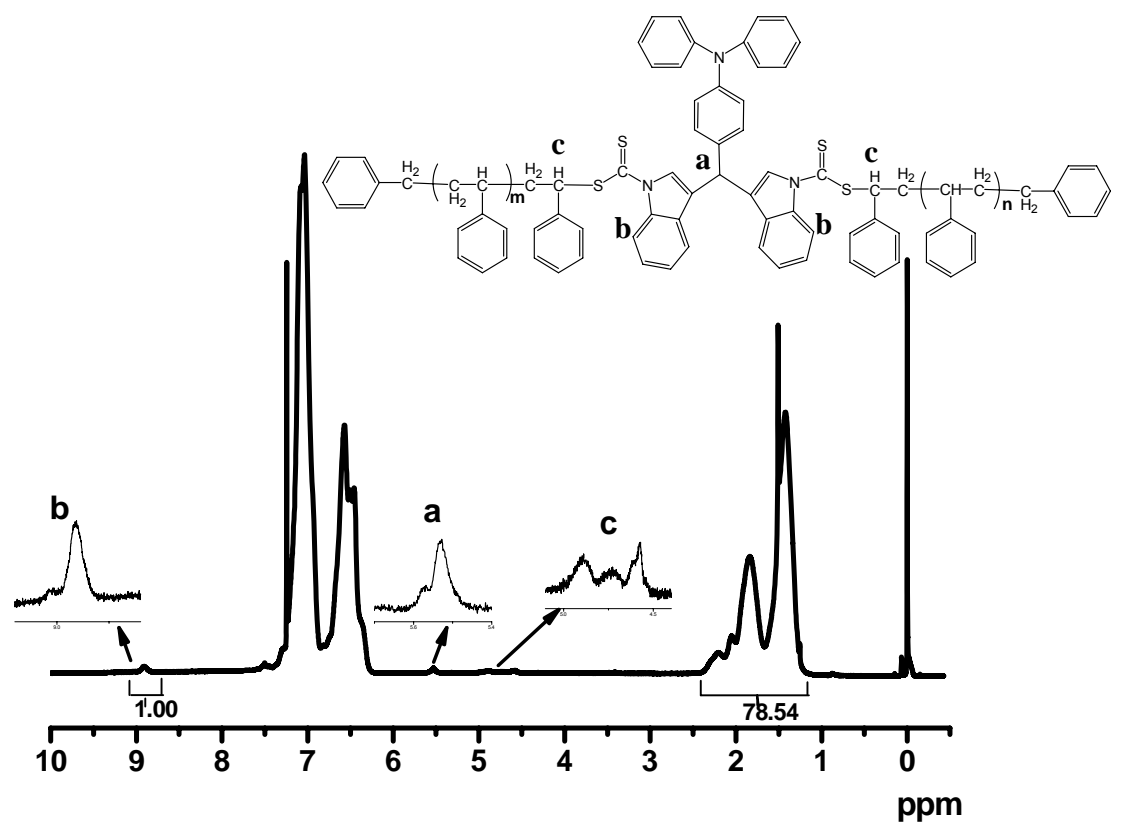

Fig. 3. Typical ${ }^{1} \mathrm{H}$ NMR spectrum of PS prepared via RAFT polymerization using BCIMPDPA as the RAFT agent $\left(\mathrm{CDCl}_{3}\right) .\left(M_{\mathrm{n}(\mathrm{GPC})}=6200, M_{\mathrm{w}} / M_{\mathrm{n}}=1.37\right)$.

To further confirm the "living"/controlled fashion of the polymerization, the chain extension reaction was also carried out. A typical chain extension experiment of the PS was carried out using the PS $\left(M_{\mathrm{n}(\mathrm{GPC})}=33600, M_{\mathrm{w}} / M_{\mathrm{n}}=1.24\right)$ as the macro-RAFT agent and St as monomer in anisole solution ([St] $]_{0}$ : [macro-RAFT agent] $=500: 1$, at $110{ }^{\circ} \mathrm{C}$ for $7 \mathrm{~h}$, conversion $=18.1 \%$ ). GPC curves of the original and chain-extended polymers are shown in Figure 4. An obvious peak shift, the molecular weight increased from 33600 to 42900 , and the $M_{\mathrm{w}} / M_{\mathrm{n}}$ of the polymers changed from 1.24 to 1.39 which indicated that the most of the original polymer chains contained the moieties of RAFT agent and were still 'living'. 


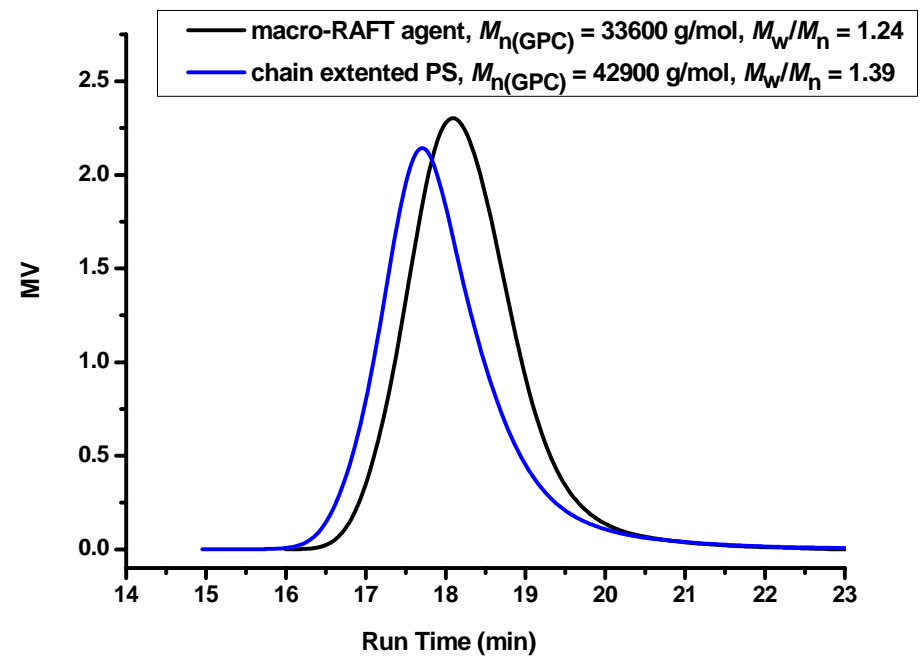

Fig. 4. GPC curves of the original and chain extented PS. (a) polymer before chain extension, $M_{\mathrm{n}(\mathrm{GPC})}=33600, M_{\mathrm{w}} / M_{\mathrm{n}}=1.24$; (b) polymer after chain extension, $M_{\mathrm{n}(\mathrm{GPC})}$ $=42900, M_{\mathrm{w}} / M_{\mathrm{n}}=1.39\left([\mathrm{St}]_{0}:[\text { macro-RAFT agent }]_{0}=500: 1, \mathrm{~T}=110^{\circ} \mathrm{C}, \mathrm{t}=7 \mathrm{~h}\right.$, conversion $=18.1 \%$ ).

Optical properties of the RAFT agent (BCIMPDPA) and the corresponding polymers

Due to the high sensitivity of the triphenylamine, indole, and dithiocarbamate (DC ) groups to the UV light, the UV absorption of the RAFT agent (BCIMPDPA), the corresponding polymers (PS1, PS2) and the blank sample polystyrene (PS) in THF were measured as shown in Figure 5.

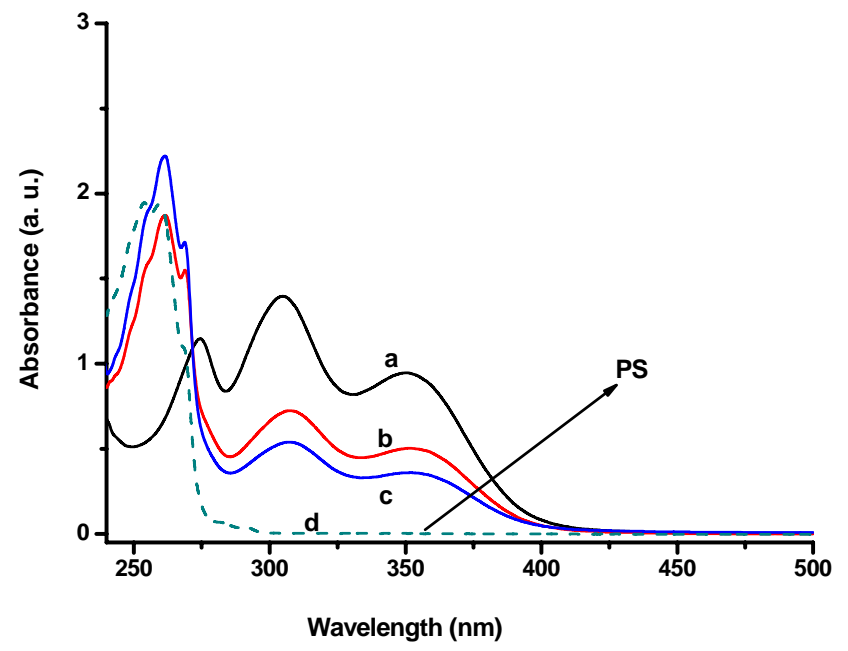

Fig. 5. UV-vis spectra of BCIMPDPA, center-functioned PS1 and PS2, and blank sample $\mathrm{PS}$ in $\mathrm{CHCl}_{3}$ solution. The concentration of triphenylamine and bis(indolyl)methyne moiety is $2.5 \times 10^{-5} \mathrm{~mol} / \mathrm{L}$. The concentration of benzyliene moiety in blank sample (PS) is the same as PS1. (a) BCIMPDPA; (b) PS1: $M_{\mathrm{n}(\mathrm{GPC})}=$ 26300, $M_{\mathrm{w}} / M_{\mathrm{n}}=1.41$; (c) PS2: $M_{\mathrm{n}(\mathrm{GPC})}=33600, M_{\mathrm{w}} / M_{\mathrm{n}}=1.24$; (d) PS: the blank sample. 
From Figure 5, it can be found that both BCIMPDPA and the corresponding polymers (PS1, PS2) showed strong absorption peaks at around $350 \mathrm{~nm}$ and $305 \mathrm{~nm}$, respectively, which corresponded to the absorptions of the TPA and DC moieties, respectively. Moreover, the characteristic absorption peak at around $275 \mathrm{~nm}$ in BCIMPDPA corresponded to the absorption of the indole moiety, which was not so obvious in the corresponding polymers (PS1, PS2) due to the overlapped absorption band peak at around $263 \mathrm{~nm}$ corresponding to benzyliene in PS. These results further indicated that the TPA and indole moieties in Z group were successfully linked with the chain-center PS.

Furthermore, the strong fluorescence of triphenylamine in solution can be observed, which is attributed to the rigid conjugated structure. The fluorescence of BCIMPDPA and the corresponding polymers (PS1) are shown in Figure 6. It can be observed that TPA labeled PS1 exhibited strong fluorescence in a wide range of wavelengths in $\mathrm{CHCl}_{3}$ at room temperature with excitation wavelength $\lambda_{\mathrm{ex}}=381 \mathrm{~nm}$. The maximum emission wavelength was around $510 \mathrm{~nm}$. However, it can be seen that BCIMPDPA exhibited less emission intensity than the obtained PS1 with the maximum wavelength around $450 \mathrm{~nm}$ at the same concentration of TPA moiety. The reasons may be due to the self-quenching effect of intermolecular, which would be reduced to a low level or even disappeared in the obtained polymer due to the weaker molecular movement of the obtained polymer than the RAFT agent [32].

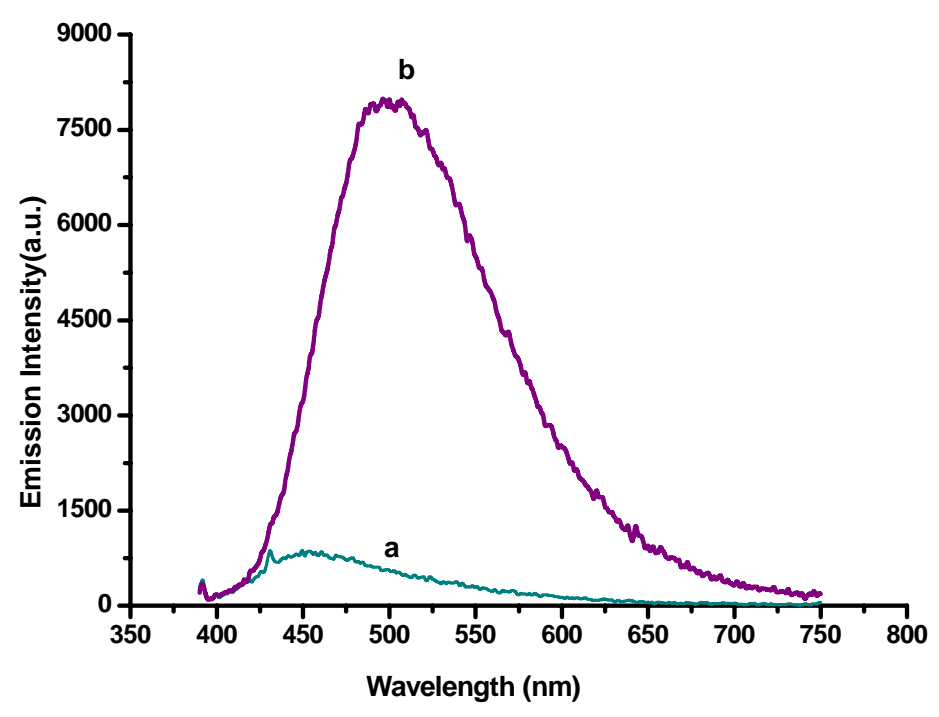

Fig. 6. Fluorescence spectra of BCIMPDPA and the center-functioned PS in $\mathrm{CHCl}_{3}$ solution at room temperature. The concentration of triphenylamine and bis(indolyl)methyne moiety is $5 \times 10^{-5} \mathrm{~mol} / \mathrm{L}\left(\lambda_{\mathrm{ex}}=381 \mathrm{~nm}\right.$ ). (a) BCIMPDPA; (b) PS1: $M_{\mathrm{n}(\mathrm{GPC})}=26300, M_{\mathrm{w}} / M_{\mathrm{n}}=1.41$.

In addition, cyclic voltammetry of BCIMPDPA and PS obtained were also carried out. Figure 7 shows the cyclic voltammograms of BCIMPDPA and the center-functioned PS $\left(M_{\mathrm{n}(\mathrm{GPC})}=6200, M_{\mathrm{w}} / M_{\mathrm{n}}=1.37\right)$ in $\mathrm{CH}_{3} \mathrm{CN}$. The reversibility of the redox process was investigated. BCIMPDPA had two couples of chemical reversible oxidation and reduction peaks which were found to be $E_{O X}=-0.68 \mathrm{~V}, E_{R E}=-1.17 \mathrm{~V}$ and $E_{O X}=0.99$ $\mathrm{V}, E_{R E}=0.87 \mathrm{~V}(\mathrm{vs} . \mathrm{Pt})$, respectively. Similarly, the center-functioned PS $\left(M_{\mathrm{n}(\mathrm{GPC})}=\right.$ 
$\left.6200, M_{\mathrm{w}} / M_{\mathrm{n}}=1.37\right)$ also exhibited chemical reversible oxidation and reduction peaks of $E_{O X}=-0.68 \mathrm{~V}, E_{R E}=-1.25 \mathrm{~V}$ (vs. $\mathrm{Pt}$ ), which also proved that the triphenylamine (TPA) and bis(indolyl)methane (BIM) moieties of the RAFT agent were successfully attached to the center of the polymer chain.

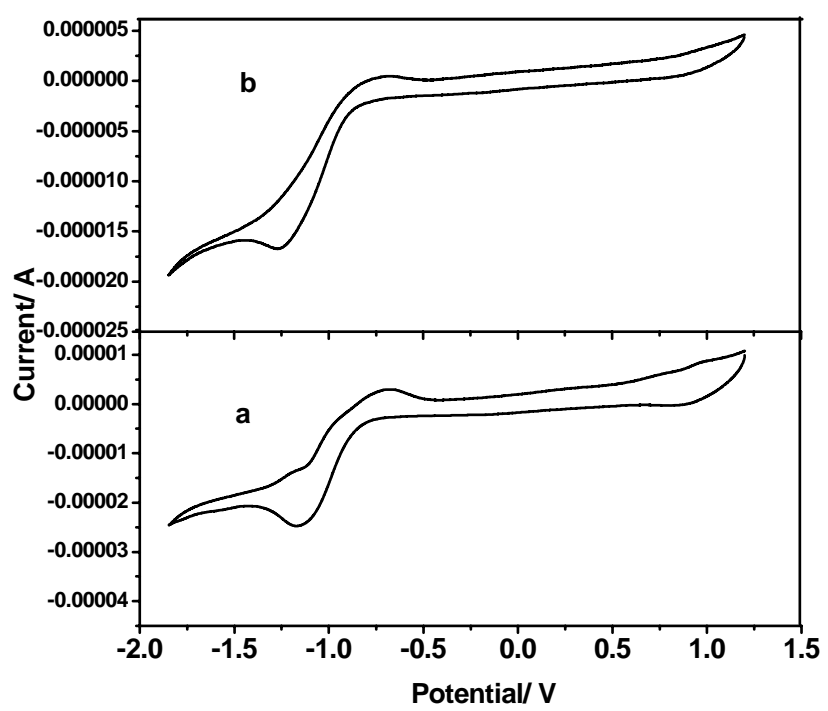

Fig. 7. Cyclic voltammograms of BCIMPDPA (a) and the center-functioned PS $\left(M_{\mathrm{n}(\mathrm{GPC})}=6200, M_{\mathrm{w}} / M_{\mathrm{n}}=1.37\right)$ (b) in $\mathrm{CH}_{3} \mathrm{CN}$ with $0.1 \mathrm{~mol} / \mathrm{L}\left(\mathrm{C}_{4} \mathrm{H}_{9}\right)_{4} \mathrm{NPF}_{6}$ at room temperature. Working electrode: Platinum plate; counter electrode: Platinum loop; reference electrode: Platinum wire. Scan rate: $50 \mathrm{Mv} / \mathrm{s}$.

\section{Conclusions}

A novel \{4-[bis(1-carbodithioic acid benzyl ester-indol-3-yl)methyl]phenyl\} diphenylamine (BCIMPDPA) bearing triphenylamine (TPA) and bis(indolyl)methane (BIM) groups in Z group was synthesized and used as the bis-functional RAFT agent in the RAFT polymerization of St. The polymerization showed typical 'living'/controlled free radical polymerization behavior. The obtained PS showed typical optical properties of the TPA and indole, such as fluorescence and UV absorption and electrochemical performance such as cyclic voltammetry.

\section{Experimental part}

\section{Materials}

4-(N,N-Diphenylamino) benzaldehyde was purchased from Aldrich Chemical Co. and tetra- $n$-butylammonium hexafluorophosphate was purchased from Alfa Aesar China (Tian Jin) LTD., which were both used as received. The styrene (St) was washed with $5 \%$ sodium hydroxide aqueous solution for three times and then with deionized water until neutralization. After being dried with anhydrous magnesium sulfate, the monomer was distilled under reduced pressure and kept in a refrigerator under $0{ }^{\circ} \mathrm{C}$ before use. $\mathrm{N}, \mathrm{N}$-Dimethyl formamide (DMF), chloroform $\left(\mathrm{CHCl}_{3}\right)$ and anisole were distilled under vacuum before use. Unless otherwise specified, all chemicals were purchased from Shanghai Chemical Reagents Co., China and used as received. 
Synthesis of $\{4-[$ bis(1H-indol-3-yl) methyl]phenyl\}diphenylamine (BIMPDPA)

A mixture of 4-(N,N-diphenylamino) benzaldehyde $(2.73 \mathrm{~g}, 10 \mathrm{mmol})$, indole $(2.34 \mathrm{~g}$, $20 \mathrm{mmol})$ and $\mathrm{I}_{2}(0.05 \mathrm{~g}, 2 \mathrm{mmol})$ in acetonitrile $(100 \mathrm{~mL})$ was stirred at room temperature for a few minutes (Scheme 1). After completeness of the reaction (TLC, $<9 \mathrm{~min})$, the mixture was treated with aq. $\mathrm{Na}_{2} \mathrm{~S}_{2} \mathrm{O}_{3}$ solution $(5 \%, 100 \mathrm{~mL})$, then the product was extracted with ethyl acetate $(3 \times 50 \mathrm{~mL})$. The combined organic layer was dried with anhydrous sodium sulphate, concentrated under vacuum and purified by column chromatography using mixture of ethyl acetate and petroleum ether $(1: 5$, $\mathrm{v} / \mathrm{v})$ as eluent. The pure BIMPDPA was obtained. ${ }^{1} \mathrm{H}$ NMR $\left(\mathrm{CDCl}_{3}, \delta\right): 5.84(\mathrm{~s}, 1 \mathrm{H}$, $\mathrm{CH}-$ ); 6.69-6.72 (d, 2H, -NCH=C-); 6.92-7.14 (m, 9H, aromatic); 7.16-7.32 (m, 9H, aromatic); 7.35-7.39 (d, 2H, aromatic); 7.41-7.48 (d, 2H, aromatic); 7.91 (s, 2H, -NH-) Elemental Analysis Calculated (\%): C 85.40, H 5.42, N 8.52; Found: C 85.86, H 5.56, N, 8.58.

Synthesis of \{4-[bis(1-carbodithioic acid benzyl ester-indol-3-yl) methyl]phenyl\} diphenylamine (BCIMPDPA)

As shown in Scheme 1, after a suspension of $\mathrm{NaOH}(0.16 \mathrm{~g}, 4 \mathrm{mmol})$ in DMF $(5 \mathrm{~mL})$ was prepared, BIMPDPA $(0.98 \mathrm{~g}, 2 \mathrm{mmol})$ was added slowly under vigorous stirring. The solution kept stirring for another $2 \mathrm{~h}$ at room temperature and then $\mathrm{CS}_{2}(0.30 \mathrm{~g}, 4$ $\mathrm{mmol}$ ) was added dropwise slowly. The resultant reddish orange solution was stirred for another $3 \mathrm{~h}$ at room temperature. Then benzyl bromide $(0.68 \mathrm{~g}, 4 \mathrm{mmol})$ was added and the mixture was stirred for about $7 \mathrm{~h}$ at room temperature. The crude yellow product was precipitated by addition of water $(50 \mathrm{~mL})$ and purified by column chromatography using mixture of ethyl acetate and petroleum ether $(1: 50, \mathrm{v} / \mathrm{v})$ as eluent to afford the pure product. ${ }^{1} \mathrm{H}$ NMR $\left(\mathrm{CDCl}_{3}, \delta\right): 4.52-4.60\left(\mathrm{~m}, 4 \mathrm{H},-\mathrm{SCH}_{2} \mathrm{Ar}\right)$; 5.58 (s, $1 \mathrm{H},-\mathrm{CH}$ ); 6.89-7.07 (m, 8H, aromatic); 7.08-7.44 (m, 22H, aromatic); 7.597.64 (s, 2H, $-\mathrm{NCH}=\mathrm{C}-)$; 8.95-9.05 (d, 2H, aromatic ). MS (m/z, \%): $821\left(\mathrm{M}^{+}, 4\right), 655$ (60), 489 (100), 372 (26), 91 (41).

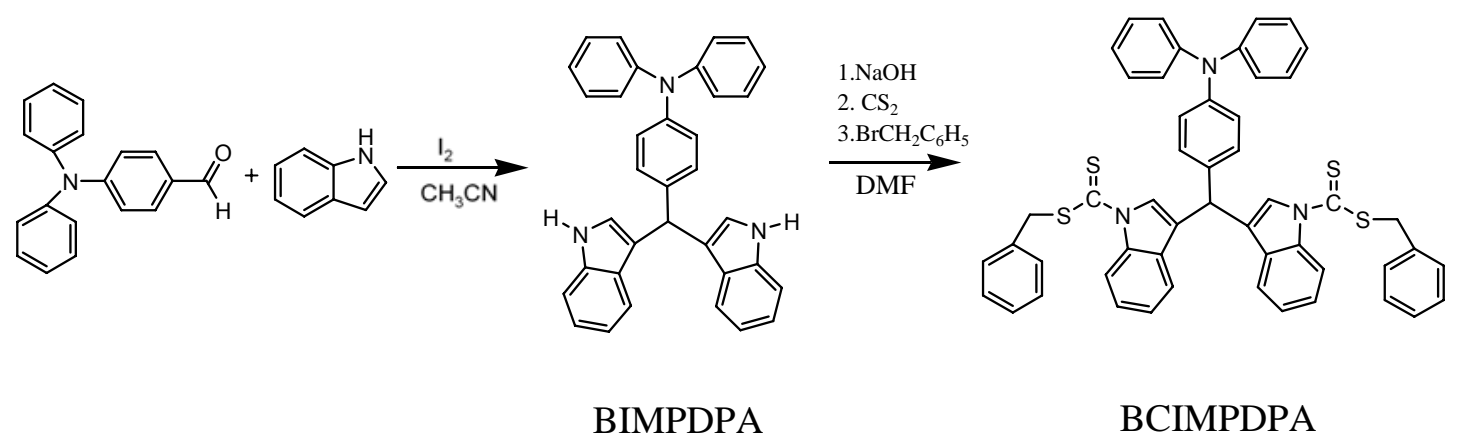

Scheme 1. Synthetic routes of $\{4-[\mathrm{bis}(1-\mathrm{carbodithioic} \mathrm{acid} \mathrm{benzyl} \mathrm{ester-indol-3-}$ yl)methyl]phenyl\}diphenylamine (BCIMPDPA).

\section{RAFT Polymerization of St}

The typical procedures of RAFT polymerization of St was as follows: a stock solution of St (11 mL, $95.48 \mathrm{mmol})$ and BCIMPDPA (98.5 mg, $0.12 \mathrm{mmol})$ was prepared, and aliquots of $1 \mathrm{~mL}$ were placed in each ampoule. The content was purged with argon for approximately 10 min to eliminate the oxygen. Then the ampoules were flame sealed and placed in an oil bath held by a thermostat at $115^{\circ} \mathrm{C}$ to polymerize. After a 
preset reaction time, each ampoule was cooled with ice water and opened. The reaction mixture was diluted with proper tetrahydrofuran (ca. $2 \mathrm{~mL}$ ) and precipitated in a large amount of methanol (ca. $300 \mathrm{~mL}$ ). The polymer was obtained by filtration and dried at $50{ }^{\circ} \mathrm{C}$ in vacuum to a constant weight. The conversion of polymerization was determined gravimetrically.

\section{Characterizations}

The molecular weight and molecular weight distribution of the PS was determined with a Waters 1515 gel permeation chromatographer (GPC) equipped with refractive index detector, using HR1, HR3, and HR4 column with molecular weight range 100500,000 calibrated respectively with PS standard samples. Tetrahydrofuran (THF) was used as the eluent at a flow rate of $1.0 \mathrm{~mL}$ min $^{-1}$ operated at $30{ }^{\circ} \mathrm{C}$. ${ }^{1} \mathrm{H}$ NMR spectra were recorded on an INOVA $400 \mathrm{MHz}$ nuclear magnetic resonance instrument, using $\mathrm{CDCl}_{3}$ as a solvent and tetramethylsilane (TMS) as the internal standard. The fluorescence emission spectra were obtained on an Ediburger FLS920 fluorescence spectrophotometer with $\mathrm{CHCl}_{3}$ as solvent at room temperature. The elemental analyses for $\mathrm{C}, \mathrm{H}$, and $\mathrm{N}$ were performed on a LECO-CHNS microanalyzer. High resolution Mass spectrum was obtained using GCT-TOF instrument. The UV absorption spectra were determined on a UV 240 spectrophotometer. Cyclic voltammetry (CV) measurements were carried out on a CHI631B electrochemical workstation, using millimolar solutions in $\mathrm{CH}_{3} \mathrm{CN}$ containing $0.1 \mathrm{M}$ supporting electrolyte of tetra- $n$-butylammonium hexafluorophosphate in a three-electrode cell.

\section{Acknowledgements}

The financial support for this work by the National Nature Science Foundation of China (No.20574050), the Science and Technology Development Planning of Jiangsu Province (No. BK2007702 and BK2007048), and the Nature Science Key Basic Research of Jiangsu Province for Higher Education (No. 05KJA15008) are gratefully acknowledged.

\section{References}

[1] Pyun, J.; Zhou, X. Z.; Drockenmuller, E.; Hawker, C. J. J. Mater. Chem. 2003, 13, 2653.

[2] Kumar, G. S.; Neckers, D. C. Chem. Rev. 1989, 89, 1915.

[3] Kronek, J.; Luston, J.; Bohme, F.; Komber, H. Macromol. Symp. 2001, 170, 301.

[4] Kronek, J.; Luston, J.; Bohme, F.; Komber, H. Macromol. Symp. 2001, 164, 105.

[5] Wang, G.; Zhu, X. L.; Cheng, Z. P.; Zhu, J. J. Polym. Sci. Part A: Polym. Chem. 2005, 43, 2358.

[6] Nianchen, Z.; Lude, L.; Xiulin, Z.; Xujie, Y.; Xin, W.; Jian, Z.; Zhenping, C. J. Appl. Polym. Sci. 2006, 99, 3535.

[7] Grodzinski, J. J. React. Funct. Polym. 2001, 49, 1.

[8] (a) Solomon, D. H.; Rizzardo, E.; Cacioli, P. US. Patent 4581429 (1986); (b) Moad, G.; Rizzardo, E.; Solomon, D. H. Macromolecules 1982, 15, 909; (c) Georges, M. K.; Veregin, R. P. N.; Kazmaier, P. M.; Hamer, G. K. Macromolecules 1993, 26, 2987; (d) Hawker, C. J.; Bosman, A. W.; Harth, E. Chem. Rev. 2001, 101, 3661.

[9] (a) Wang, J. S.; Matyjaszewski, K. J. Am. Chem. Soc. 1995, 117, 5614; (b) Wang, J. S.; Matyjaszewski, K. Macromolecules 1995, 28, 7901; (c) Matyjaszewski, K.; Xia, J. Chem. Rev. 2001, 101, 2921. 
[10] (a) Kato, M.; Kamigaito, M.; Sawamoto, M.; Higashimura, T. Macromolecules 1995, 28, 1721; (b) Kamigaito, M.; Ando, T.; Sawamoto, M. Chem. Rev. 2001, 101, 3689 .

[11] (a) Chiefari, J.; Chong, Y. K.; Ercole, F.; Grstina, J.; Jeffery, J.; Le, T. P. T.; Mayadunne, R. T. A.; Meijs, G. F.; Moad, C. L.; Moad, G.; Rizzardo, E.; Thang, S. H. Macromolecules 1998, 31, 5559; (b) Chong, Y. K.; Le, P. T.; Moad, G.; Rizzardo, E.; Thang, S. H. Macromolecules 1999, 32, 2071.

[12] (a) Moad, G.; Rizzardo, E.; Tang, S. H. Aust. J. Chem. 2005, 58, 379; (b) Moad, G.; Rizzardo, E.; Thang, S. H. Aust. J. Chem. 2006, 59, 669; (c) Arnaud Favier, A.; Charreyre, M. T. Macromol. Rapid. Commun. 2006, 27, 653; (d) Perrier, S.; Takolpuckdee, P. J. Polym. Sci. Part A: Polym. Chem. 2005, 43, 5347.

[13] Barner-Kowollik, C.; Davis, T. P.; Heuts, J. P. A.; Stenzel, M. H.; Vana, P.; Whittaker, M. J. Polym. Sci., Part A: Polym. Chem. 2003, 41, 365.

[14] Liu, J.; Hong, C. Y.; Pan, C. Y. Polymer 2004, 45, 4413.

[15] Jiang, J.; Thayumanavan, S. Macromolecules 2005, 38, 5886.

[16] Zhou, G.; Harruna, I. I. Macromolecules 2005, 38, 4114.

[17] Lepoittevin, B.; Matmour, R.; Francis, R.; Taton, D.; Gnanou, Y. Macromolecules 2005, 38, 3120.

[18] Hao, X.; Heuts, J. P. A.; Barner-Kowollik, C.; Davis, T. P.; Evans, E. J. Polym. Sci. Part A: Polym. Chem. 2003, 41, 2949.

[19] Lima, V.; Jiang, X.; Brokken-Zijp, J.; Schoenmakers, P. J.; Klumperman, B.; Linde, R. V. D. J. Polym. Sci. Part A: Polym. Chem. 2005, 43, 959.

[20] Yuan, J. J.; Ma, R.; Gao, Q.; Wang, Y. F.; Cheng, S. Y.; Feng, L. X.; Fan, Z. Q.; Jiang, L. J. Appl. Polym. Sci. 2003, 89, 1017.

[21] Ran W.; Charles L. M.; Andrew B. L. Macromolecules 2005, 38, 9518.

[22] Hong, C. Y.; Pan, C. Y. Macromolecules 2006, 39, 3517.

[23] Tang, C. W.; VanSlyke, S. A. Appl. Phys. Lett. 1987, 51, 913.

[24] Adachi, C.; Nagai, K.; Tamoto, N. Appl. Phys. Lett. 1995, 66, 2679.

[25] Strohriegl, P.; Grazulevicius, J. V. Adv. Mater. 2002, 14, 1439.

[26] Jian, P. L.; Ping, F. X.; Pik, K. L.;Ye, T.; Man, S. W. Chem. Mater. 2006, 18, 6194.

[27] Behl, M.; Hattemer, E.; Brehmer, M.; Zentel, R. Macromol. Chem. Phys. 2002, 203, 503.

[28] Sundberg, R. J. The Chemistry of Indoles; Academic Press: New York, 1970.

[29] Zeligs, M. A. J. Med. Food 1998, 1, 67.

[30] (a) Moad, G.; Rizzardo, E.; Thang, S. H. Aust. J. Chem. 2005, 58, 379. (b) Moad, G.; Rizzardo, E.; Thang, S. H. Aust. J. Chem. 2006, 59, 669. (c) Favier, A.; Charreyre, M. T. Macromol. Rapid Commun. 2006, 27, 653.

[31] Chong, Y. K.; Krstina, J.; Le, T. P. T.; Moad, G.; Rizzardo, E.; Thang, S. H. Macromolecules 2003, 36, 2256.

[32] Zhou, D.; Zhu, X.; Zhu, J.; Hu, L.; Cheng, Z. J. Appl. Polym. Sci.2007, 103, 982. 